guidance at the selected host institution. Additionally, all awardees will receive complimentary registration to the Association's 2013 Annual Meeting and postgraduate courses taking place May 4-8, 2013, in Minneapolis, Minnesota.

For more information and to submit an application please visit the AATS Web site at www.aats.org. Application Deadline: January 15, 2013

\section{AATS Mitral Conclave}

Decision Making, Outcomes, \& Surgical Video Sessions, www.aats.org/mitral

\section{Call for Abstracts/Videos}

Submission Deadline: January 3, 2013

\section{PROGRAM DIRECTOR}

David H. Adams

\section{PROGRAM COMMITTEE}

Anelechi C. Anyanwu

Michael A. Borger

Pedro J. del Nido

Robert J. M. Klautz

Irving L. Kron

Tomislav Mihaljevic

D. Craig Miller

The 2013 AATS Mitral Conclave will bring the world's leading figures in mitral valve disease together for two days to discuss the latest information regarding management guidelines, imaging, pathology, minimally invasive approaches, percutaneous approaches, surgical techniques, devices, and long-term results. Faculty presentations of the latest available data, techniques, and state-of-the-art reviews will be supplemented by abstract and video presentations selected by the program committee from submitted original work. Selected manuscripts from accepted presentations will be considered for publication in a supplement to The Journal of Thoracic and Cardiovascular Surgery.
On behalf of the Program Committee, we invite you to submit your abstract and video for consideration to the 2013 AATS Mitral Conclave. Abstracts are limited to 450 words. You may use ONE image OR ONE table within your abstract, which will NOT deduct from the word count.

\section{Accepting Abstracts and Videos in the following} categories:

- Degenerative Valve Disease

- Mitral Regurgitation in Heart Failure

- Ischemic Mitral Regurgitation

- Rheumatic Mitral Valve Disease

- Mitral Valve Endocarditis

- Congenital Mitral Valve Disease

- Other Mitral Valve Disease

- Repair Techniques \& Strategies

- Mitral Valve Replacement

- Long Term Outcomes

- AFib in Mitral Valve Disease

- Tricuspid Valve Disease

Video Submissions

If submitting a video, you MUST submit an abstract via the abstract submission site. All submissions must include an abstract with a maximum of 450 words. Videos may not exceed 5 minutes in length. Complete submission guidelines can be found online at www.aats.org/mitral.

\section{Accreditation}

The American Association for Thoracic Surgery is accredited by the Accreditation Council for Continuing Medical Education to provide continuing medical education for physicians.

This activity has been approved for AMA PRA Category 1 Credits $^{\mathrm{TM}}$.

For more information on the 2013 AATS Mitral Conclave, or on submitting and abstract/video for consideration, please contact mitral@aats.org or visitwww.aats.org/mitral.

\section{The Western Thoracic Surgical Association}

\section{Applications for Membership}

The WTSA Application for Membership is now online and must be submitted electronically. A candidate's application must include the following uploads: a photo, a complete curriculum vitae with bibliography, and the 3 most significant articles that $\mathrm{s} / \mathrm{he}$ personally wrote. The candidates electronic membership application must be completed and submitted online by March 1, 2013, and all support letters uploaded by that candidates sponsors by March 31, 2013, in order for the candidate to be considered for election to membership at the 2013 Annual Meeting. Visit the WTSA Web site at www.westernthoracic.org to read membership eligibility requirements and to initiate an online application. 